\title{
Rare Case of Lupus Nephritis With Negative Antinuclear Antibodies, Double-Stranded DNA Antibodies and Positive Anti-Ro/SSA Antibodies
}

\author{
Mohammad Abu-Hishmeh ${ }^{\mathrm{a}, \mathrm{c}}$, Alamgir Sattar ${ }^{\mathrm{a}}$, Z. Zarlasht ${ }^{\mathrm{a}}$, Mohamed Ramadan ${ }^{\mathrm{a}}$, \\ Aisha J. Abdel-Rahman ${ }^{\text {a }}$, Shante A. Hinson ${ }^{\mathrm{a}, \mathrm{b}}$, Nehad Shabarek ${ }^{\mathrm{a}}$
}

\begin{abstract}
Systemic lupus erythematosus (SLE) is an autoimmune multisystem disease that is characterized by various antibodies to nuclear and cytoplasmic antigens and diagnosed by either fulfilling the 2012 Systemic Lupus International Collaborating Clinics (SLICC) criteria, American College of Rheumatology (ACR) criteria or by Renal Biopsy. Renal involvement is common in SLE and is primarily related to anti-double-stranded DNA antibodies. However, small group of SLE nephritis patients have shown negative anti-dsDNA and ANA. We present a case of 25-year-old female who presented with proteinuria and negative serum antibodies except anti-Ro/SSA. Renal biopsy was performed and was consistent with class IV lupus nephritis (LN). In this report, we highlight the possible role of antiRo antibodies in the pathogenesis and the prognosis of LN, although the mechanism is yet to be understood. Anti-Ro/SSA antibodies might play an important role in the pathogenesis and prognosis in LN. However, further studies are required to understand the exact mechanism.
\end{abstract}

Keywords: Systemic lupus erythematosus; Anti-double-stranded DNA antibodies; Lupus nephritis

\section{Introduction}

Systemic lupus erythematosus (SLE) is an autoimmune multisystem disease which is diagnosed by either fulfilling the 2012 Systemic Lupus International Collaborating Clinics (SLICC) criteria, American College of Rheumatology (ACR) or by Renal Biopsy [1]. Renal involvement is a common complication

Manuscript accepted for publication June 24, 2016

aDepartment of Medicine, Lincoln Medical and Mental Health Center, Bronx, NY, USA

bDepartment of Rheumatology, Lincoln Medical and Mental Health Center, Bronx, NY, USA

${ }^{\mathrm{c} C o r r e s p o n d i n g ~ A u t h o r: ~ M o h a m m a d ~ A b u ~ H i s h m e h, ~ D e p a r t m e n t ~ o f ~ M e d i c i n e, ~}$ Lincoln Medical and Mental Health Center, 2562 Laconia Ave, Bronx, NY 10469, USA.Email: memaad@hotmail.com

doi: http://dx.doi.org/10.14740/wjnu272e of SLE affecting almost half of the patients [2] and autoantibodies such as anti-dsDNA play a major role in its pathogenesis and activity. In this report, we will discuss a rare case of a young female diagnosed with lupus nephritis (LN), with only anti-Ro/SSA antibodies being positive.

\section{Case Report}

A 25-year-old female presented to our hospital because of chest pain and frontal headache for 2 weeks, associated with orthopnea, leg swelling and easy fatigability. She had no history of skin rashes, hypersensitivity, fever, oral ulcers, dry mouth or eyes, joint pains, and recent sore throat or skin infections. She had no past medical history and her family history was unremarkable for renal or rheumatological diseases.

On physical examination, her blood pressure was elevated 188/130 mm Hg, and no pedal edema, skin rashes or joint swelling were noted. Her abdominal, respiratory and cardiovascular examination was unremarkable.

Her complete blood count (CBC) showed microcytic anemia with hemoglobin of $9.6 \mathrm{~g} / \mathrm{dL}$ and mean corpuscular volume of $76 \mathrm{fL}$, and the leukocyte and platelet counts were normal. The renal function test showed a picture of chronic kidney disease with blood urea nitrogen of $69 \mathrm{mg} / \mathrm{dL}$, serum creatinine of $5.8 \mathrm{mg} / \mathrm{dL}$, low calcium level of $6.9 \mathrm{mg} / \mathrm{dL}$ and elevated phosphorus level of $6.9 \mathrm{mg} / \mathrm{dL}$. Her total protein and albumin levels were low at 4.8 and $2.8 \mathrm{~g} / \mathrm{dL}$, respectively. The urine studies were significant for $3+$ proteinuria, red blood cells and course granular casts. Random urine protein to creatinine ratio was significantly elevated (8.24). Thyroid stimulating hormone and blood glucose levels were normal, and tests for HIV, hepatitis B and hepatitis C were negative. Her serology was positive only for anti-Ro/SSA antibodies by immunoassay 1.8 AI (reference value $<1 \mathrm{AI}$ ). ANA, anti-dsDNA, ASO, anti-La, anti-smith and anti-U1RNP antibodies were all negative. Erythrocyte sedimentation rate (ESR) was elevated at $30 \mathrm{~mm}$ in the first hour, with normal C-reactive protein of $0.79 \mathrm{mg} / \mathrm{L}$ and complement $\mathrm{C} 3$ of $115 \mathrm{mg} / \mathrm{dL}$, and her $\mathrm{C} 4$ level was elevated at $53 \mathrm{mg} / \mathrm{dL}$.

Renal ultrasound was unremarkable, with right kidney measuring $10.5 \mathrm{~cm}$ in length and left kidney measuring 10.2 $\mathrm{cm}$ in length. Biopsy of the left kidney was performed under computed tomography guidance, and microscopic evaluation 
of the specimen showed 11 glomeruli, of which three glomeruli were completely sclerosed, and five glomeruli showed cellular crescent. There was diffuse and prominent interstitial inflammation comprising of lymphocytes and few neutrophils. Ultrastructural evaluation of one glomerulus by electron microscope demonstrated many immune-type electron-dense deposits predominantly at subepithelial and mesangial locations. Unfortunately, no immunofluorescence microscopy evaluation was done because no glomeruli were seen on tissue submitted for immunofluorescence, but the pathology findings were suggestive of proliferative (class IV) LN.

The patient was started on pulse steroid therapy with methyl-prednisone $1 \mathrm{~g}$ /day for 3 days then $1 \mathrm{mg} / \mathrm{kg}$ of prednisone daily along with mycophenolate and hydroxychloroquine. One month later, hemodialysis was started because of hyperkalemia and fluid overload. After 6 months, the patient is still dependent on hemodialysis and has not shown clinical signs or symptoms of SLE.

\section{Discussion}

SLE is an autoimmune multisystem disease that is characterized by various antibodies to nuclear and cytoplasmic antigens. Renal involvement is a common complication of SLE affecting almost half of the patients [2]. Although antibodies against DNA play a major role in the pathogenesis and the activity of LN [3-5], there are few cases in the literature of LN with no detectable antibodies $[6,7]$.

Our patient has a renal biopsy suggestive of LN but did not fulfill the SLICC criteria because there were no antibodies detected except the anti-Ro/SSA which is not part of it. Anti-Ro/SSA antibodies have been associated with Sjogren's syndrome and neonatal lupus erythematosus (NLE) along with fetal heart conduction abnormalities [8]. The role of anti-Ro/ SSA in LN is not established yet, some studies have shown that it has no correlation [9] while others showed that anti-Ro/SSA antibodies alone were associated with a higher prevalence of nephritis $[10,11]$. One study has evaluated 130 SLE patients and found that $48 \%$ of the patients had anti-Ro/SSA antibodies prior to the diagnosis and were the first antibodies to develop in those patients [12]. In this report, we highlight the possible role of anti-Ro antibodies in the pathogenesis of LN, although the mechanism is yet to be understood.

\section{Conclusion}

Anti-Ro/SSA antibodies might play an important role in the pathogenesis and prognosis in LN. However, further studies are required to understand the exact mechanism.

\section{References}

1. Petri M, Orbai AM, Alarcon GS, Gordon C, Merrill JT, Fortin PR, Bruce IN, et al. Derivation and validation of the Systemic Lupus International Collaborating Clinics classification criteria for systemic lupus erythematosus. Arthritis Rheum. 2012;64(8):2677-2686.

2. Cervera R, Khamashta MA, Font J, Sebastiani GD, Gil A, Lavilla P, Mejia JC, et al. Morbidity and mortality in systemic lupus erythematosus during a 10-year period: a comparison of early and late manifestations in a cohort of 1,000 patients. Medicine (Baltimore). 2003;82(5):299308.

3. Yung S, Chan TM. Autoantibodies and resident renal cells in the pathogenesis of lupus nephritis: getting to know the unknown. Clin Dev Immunol. 2012;2012:139365.

4. Egner W. The use of laboratory tests in the diagnosis of SLE. J Clin Pathol. 2000;53(6):424-432.

5. Cameron JS. Lupus nephritis. J Am Soc Nephrol. 1999;10(2):413-424.

6. Gianviti A, Barsotti P, Barbera V, Faraggiana T, Rizzoni G. Delayed onset of systemic lupus erythematosus in patients with "full-house" nephropathy. Pediatr Nephrol. 1999;13(8):683-687.

7. Simmons SC, Smith ML, Chang-Miller A, Keddis MT. Antinuclear Antibody-Negative Lupus Nephritis with Full House Nephropathy: A Case Report and Review of the Literature. Am J Nephrol. 2015;42(6):451-459.

8. Alexander E, Buyon JP, Provost TT, Guarnieri T. AntiRo/SS-A antibodies in the pathophysiology of congenital heart block in neonatal lupus syndrome, an experimental model. In vitro electrophysiologic and immunocytochemical studies. Arthritis Rheum. 1992;35(2):176-189.

9. Alba P, Bento L, Cuadrado MJ, Karim Y, Tungekar MF, Abbs I, Khamashta MA, et al. Anti-dsDNA, anti-Sm antibodies, and the lupus anticoagulant: significant factors associated with lupus nephritis. Ann Rheum Dis. 2003;62(6):556-560.

10. Harley JB, Sestak AL, Willis LG, Fu SM, Hansen JA, Reichlin M. A model for disease heterogeneity in systemic lupus erythematosus. Relationships between histocompatibility antigens, autoantibodies, and lymphopenia or renal disease. Arthritis Rheum. 1989;32(7):826-836.

11. Wasicek CA, Reichlin M. Clinical and serological differences between systemic lupus erythematosus patients with antibodies to Ro versus patients with antibodies to Ro and La. J Clin Invest. 1982;69(4):835-843.

12. Arbuckle MR, McClain MT, Rubertone MV, Scofield RH, Dennis GJ, James JA, Harley JB. Development of autoantibodies before the clinical onset of systemic lupus erythematosus. N Engl J Med. 2003;349(16):1526-1533. 